\title{
EL DESAFÍO A LOS JUEGOS OLÍMPICOS DE BERLÍN 1936: LOS ATLETAS JUDÍOS DE PALESTINA EN LA FRUSTRADA OLIMPIADA POPULAR DE BARCELONA
}

\author{
THE CHALLENGE TO THE 1936 BERLIN OLYMPIC \\ GAMES: THE JEWISH ATHLETES FROM PALESTINE AND \\ THE FRUSTRATED BARCELONA POPULAR OLYMPIAD
}

\author{
Raanan Rein \\ Universidad de Tel Aviv, Israel \\ orcid.org/0000-0002-0249-6084
}

Recibido el 29-1-2017 y aceptado el 20-9-2017

Resumen. El día 19 de julio de 1936 la ciudad de Barcelona albergaba a un número inusual de personas. Miles de atletas y hasta 20 mil visitantes se encontraban presentes en la ciudad para asistir a los actos de inauguración de la Olimpiada Popular que había sido convocada como desafío a los Juegos Olímpicos de Berlín de ese mismo año. Sin embargo la insurrección militar contra el gobierno electo de la Segunda República puso fin a esta iniciativa antifascista auspiciada por la Generalitat catalana. Debido a ello esta iniciativa quedaría relegada al olvido durante las décadas siguientes, recibiendo muy poca atención por parte de la historiografía dedicada a este agitado periodo de la reciente historia española.

Este artículo arroja nueva luz sobre el desafío que la Olimpiada de Barcelona planteaba al imparable crecimiento del fascismo europeo a lo largo de los años centrales de la década de 1930. Igualmente, destaca el hecho de que algunos de los atletas presentes en Barcelona durante esos días pasarían a ejercer como los primeros voluntarios en sumarse a la defensa en armas de la sitiada República. Una de las delegaciones que viajaban a Barcelona partió desde la Palestina judía. Fue esta la primera expresión de solidaridad desde el Yishuv judío con la República española y su lucha por la supervivencia.

Palabras clave: Olimpiada Popular, Juegos Olímpicos de Berlin, Guerra Civil Española, Palestina, sionismo, voluntarios internacionales. 


\begin{abstract}
On $19^{\text {th }}$ July 1936, a few hours before the scheduled opening ceremony of the Peoples' Olympiad, the military uprising against the elected government of the Second Republic broke out. Most of the athletes who had come to Barcelona departed quickly. However, some of them remained in Spain and became the first international volunteers to help in the defense of the Republic.

The Barcelona games had been planned as a response to the Olympics, about to open in Berlin, which had been hijacked to serve the Nazi propaganda. Since the Peoples' Olympiad did not take place, historiography has dedicated only little attention to this anti-fascist effort of counter-Olympics. This paper focuses on the delegation of athletes from Jewish Palestine, which consisted mainly of members of the Hapoel Sport's Federation. This was the first expression of the Yishuv's solidarity with the Spanish Republic and the anti-fascist struggle.
\end{abstract}

Keywords: Popular Olympiad; Berlin Olympic Games; Spanish Civil War; Palestine; Zionism; International volunteers. 
Chaim Elkon llegó a la Palestina judía en 1924 junto al legendario equipo de fútbol Hakoah Viena, que llegaba a disputar un partido contra Maccabi Tel Aviv. Al regresar los visitantes a Austria, Elkon resolvió quedarse en Palestina. Desde entonces militó en las filas del Partido Comunista de Palestina, cuya actividad era ilegal, hasta que fue expulsado por las autoridades mandatorias británicas. ${ }^{1}$ En julio de 1936 llegó a Barcelona para participar en la Olimpiada Popular en calidad de árbitro. Pero esos Juegos, que debían inaugurarse el 19 de aquel mes, no llegaron a realizarse. Pocas horas antes, cuando en la ciudad había cerca de 6.000 deportistas y unos 20 mil visitantes que se disponían a presenciar el acto de inauguración, estalló la revuelta militar contra el gobierno electo de la Segunda República. Este levantamiento, que llevaría finalmente al poder al general Francisco Franco, desencadenó rápidamente la que sería una larga y encarnizada guerra civil. La mayor parte de los atletas que habían llegado a la capital catalana abandonaron la ciudad lo antes posible. Elkon decidió permanecer en ella y contribuir a la defensa de la República.

También Imre Jacobi, nacido en Budapest y devenido uno de los futbolistas más destacados de Palestina en la primera mitad de la década de 1930, llegó a Barcelona en julio de 1936 y decidió permanecer en España para combatir el alzamiento nacionalista. El club judío en el que había jugado en sus años jóvenes, Hagibor Bratislava, solía salir de vez en cuando de Checoslovaquia para recaudar dinero en sus giras. Cuando llegaron en 1927 a Palestina, Imre prefirió quedarse allí. En muy poco tiempo se convirtió en capataz en la empresa Gut y Gurewitz, que llevaba a cabo trabajos de construcción de carreteras para las autoridades británicas. Las duras condiciones de explotación en que se empleaba a los obreros, árabes y judíos, llevaron a Imre a organizar a trabajadores de ambos grupos étnicos para mejorar sus condiciones laborales. A consecuencia de una de las grandes huelgas de los constructores de caminos, la gerencia de la empresa despidió a Jacobi, que por aquel entonces ya se había sumado a las filas del Partido Comunista local. Durante la represión policial en respuesta a la manifestación obrera del 1 de Mayo de 1935, Imre fue detenido por primera vez por los británicos. En los meses siguientes se su-

1 Según Centner, 1966, p. 294 y Yahav, 2008, p. 217, la orden de expulsión de Elkonse decretó ya en 1929, pero en la práctica no lo fue al menos hasta 1933. Véase los periódicos con información sobre la detención de activistas comunistas, entre ellos Elkon: Davar, 7.7.1932 y 16.8.1933. 
cedieron sus entradas y salidas de comisarías policiales, tribunales y prisiones del Mandato. ${ }^{2}$ En junio de 1936 fue expulsado de Palestina y salió rumbo a España. Cuando se enteró de que la competición popular no se iba a celebrar, decidió también él sumarse a los voluntarios extranjeros que luchaban en España, semanas antes de que el Comintern alentara la creación de las Brigadas Internacionales.

Este artículo tiene como objetivo analizar la formación y desarrollo del equipo judío de Palestina, las protestas desde aquel territorio en contra de los Juegos Olímpicos de Berlín, el viaje de los atletas judíos hasta la frontera francesa y su regreso a Palestina. Basándose en una variedad de fuentes primarias y secundarias, sobre todo en la prensa hebrea contemporánea, los boletines del comité organizador de la Olimpiada Popular y documentación de la asociación deportiva judeo-socialista Hapoel, el texto intenta ahondar en la motivación sociopolítica y la experiencia de estos atletas y sus representantes en los momentos previos al estallido de la Guerra Civil y durante sus primeras horas.

La Olimpiada Popular pretendía ofrecer una alternativa basada en el deporte popular frente al deporte olímpico competitivo. Miles de participantes llegaron desde diversos países y de todos los rincones de España para esta contra-competición que organizaron las autoridades catalanas, mas debido a que al final de cuentas no tuvo lugar, la Olimpiada Popular ha recibido escasa atención por parte de los investigadores. En el centro de este artículo se encuentra la delegación de Palestina que partió rumbo a Barcelona, integrada sobre todo por atletas de la organización deportiva Hapoel. Fue esta la primera expresión de solidaridad de la población judía de Palestina con la República Española y con la lucha anti-fascista. En los tres años siguientes (1936-1939), a pesar de estar la población judía envuelta en el fragor de la lucha con el incipiente movimiento nacional palestino, en el marco de «la gran revuelta árabe» que coincidió durante ese mismo trienio, la guerra civil en España tuvo grandes repercusiones en Palestina. Sin embargo, las expresiones de solidaridad con la República no gozaron del apoyo del establishment sionista para reclutar voluntarios que fueran a combatir a la península ibérica. ${ }^{3}$

2 Doar Hayom, 22.8.1935, p. 8; Davar, 22.5.1936; Davar, 30.5.1936; Davar, 3.6.1936.

${ }^{3}$ Rein, 2009, pp. 89-112; Rein, 2012, pp. 24-49; Rein \& Ofer, 2016, pp. 92-112. 


\section{El fracaso del boicot a los Juegos de Berlín}

A finales de abril de 1931, unas dos semanas después de que el rey Alfonso XIII abandonara España y se constituyera la Segunda República, el Comité Olímpico Internacional se reunía en la capital catalana para seleccionar la que debía ser la ciudad anfitriona de los Juegos Olímpicos de verano de 1936. Las dos candidatas eran Berlín, que debió haber sido la sede de la Olimpiada de 1916, cancelada debido a la Gran Guerra, y Barcelona, que ya había sido propuesta para las ediciones de 1920 y de $1924 .{ }^{4}$ No todos los miembros del COI llegaron a la ciudad condal; algunos enviaron su voto por correo. Si bien el reciente paso de monarquía al republicanismo había ocurrido de forma pacífica, sin derramamiento de sangre, algunos delegados albergaban temores. Pero la resolución del Comité a favor de la capital germana no era la expresión de una política conservadora o de apaciguamiento hacia el fascismo. A pesar de la crisis general en que estaba sumida, la República de Weimar se adhería aún a sus instituciones democráticas. Ninguno de los delegados asistentes a la reunión del COI podía siquiera imaginar lo que iba a ocurrir en los años subsiguientes. Una mayoría contundente, con 43 votos a favor contra 16 , resolvió conceder a la capital alemana el honor de ser la sede olímpica en 1936.5

Cuando menos de dos años después el nacionalsocialismo asumió el gobierno, comprendió muy pronto el potencial propagandístico de los JJ.OO. como un escaparate para su régimen, su visión y sus logros. Se trataba de una oportunidad para demostrar la superioridad del atletismo ario y el renacimiento de Alemania bajo el gobierno nazi. ${ }^{6}$ No obstante, desde 1935 y ante el segregacionismo impuesto a alemanes no arios en las diversas disciplinas y la militarización de la actividad deportiva, comenzó una campaña internacional para boicotear los Juegos de Berlín. Para contrarrestar estos intentos por parte de los Países Bajos o Estados Unidos, entre otros, el régimen dio marcha atrás en sus declaraciones anteriores según las cuales solamente arios podrían representar a la nación germana y que deportistas judíos extranjeros no serían bienvenidos en la capital del Reich. En la práctica, muy poco cambió en la política implementada. Las

4 Colomé, 2008, p. 5.

5 Stout, 2016, cap. 7.

${ }^{6}$ Mandell, 1986; Clay Large, 2007 y la película de Leni Riefenstahl con su versión glorificada y romántica de los Juegos, Olympia (parte 1) - Festival de las Nacions (1936). 
promesas de los representantes alemanes demostraron muy pronto no tener ningún valor y la discriminación contra los deportistas judíos continuó. Tampoco se redujo la protesta internacional. ${ }^{7}$ Las garantías dadas sobre la esperada participación de la esgrimista alemana-judía Helena Mayer, campeona olímpica y mundial en florete (quien efectivamente participó en el marco de la delegación local) y la atleta Margaret «Gretel» Bergmann (que finalmente no pudo participar en su especialidad, salto de altura) fueron realizadas para demostrar que la Alemania nazi no impedía la actividad a deportistas judíos. El Comité Olímpico Estadounidense adoptó la decisión de participar en los Juegos tras una votación que obtuvo una mayoría ínfima (61 a favor, 57 en contra) y al mismo tiempo quedó imposibilitado de apoyar cualquier iniciativa alternativa. ${ }^{8}$

\section{Deporte e identidad regional en Cataluña}

A comienzos de 1936, el panorama político de la Europa meridional estaba en transformación. En febrero asumió el poder en Madrid el nuevo gobierno, liderado por el Frente Popular, renovándose la actividad de las instituciones catalanas que habían quedado suspendidas tras la fallida intentona revolucionaria de octubre de $1934 .{ }^{9}$ A mediados de mayo también en París se imponía el Frente Popular encabezado por León Blum. ${ }^{10}$ En la atmósfera imperante a ambos lados de los Pirineos se veía con beneplácito, y en algunos círculos hasta con entusiasmo, la iniciativa de la Generalitat catalana de organizar una Olimpiada Popular para el mes de julio, dos semanas antes del inicio de los Juegos de Berlín. Sin embargo, el gobierno de Blum intentó complacer tanto a sus adeptos como a sus adversarios, al asignar 1.100.000 de francos para la participación de Francia en Berlín y cerca de la mitad de esa suma para quienes representaran al país en los Juegos populares de Barcelona. Huelga señalar que ni unos ni otros quedaron satisfechos con estas medidas.

Cataluña tenía tradición a la hora de promover el deporte popular, al alcance de todos. Sus infraestructuras para ello eran avanzadas e incluían un estadio grande y moderno construido pocos años antes, con un

\footnotetext{
7 Guttmann, 1999, pp. 31-50; Gottlieb, 1972, pp. 200-209.

8 Guttmann, 1999, pp. 31-50.

9 Shubert, 1987, cap. 8; Preston, 1975, pp. 555-578.

10 Alexander \& Graham, 1989.
} 
aforo de 72.000 espectadores, para la Expo celebrada en 1929. Su identidad regional se construía sobre una estrategia de planificación cultural que incorporaba también un componente de deporte popular y de actividad físicas en asociaciones obreras apartidistas. ${ }^{11}$ En Barcelona y el cinturón industrial que la rodea había una nutrida clase obrera, orgullosa y experimentada en las luchas sindicales, sociales y políticas. Durante la dictadura del general Miguel Primo de Rivera (1924-1930) el Estado español oprimió diversas expresiones de identidad regional catalana y el deporte se convirtió en uno de los canales legales por los que se podía fortalecer el sentimiento nacional. Sobre el epígrafe del periódico $L a$ Rambla de Barcelona, fundado a comienzos de 1930 por iniciativa de Josep Sunyol i Garrig, que era también presidente de Fútbol Club Barcelona, aparecía el lema «esport i ciutadania». Por consiguiente, no sorprende que además de las competiciones en las modalidades habituales se fueran a celebrar en las Olimpiadas Populares otros eventos que habían de festejar la variedad cultural y el reconocimiento del prójimo mediante música, teatro, folclore y danzas populares. ${ }^{12}$

La resolución del gobierno catalán de organizar esta competición alternativa fue en gran medida una manifestación autónoma y no un eslabón adicional en los Juegos de las Espartaquiadas que organizaba el movimiento comunista internacional y que contaba con el apoyo de la Unión Soviética (la primera Espartaquiada se celebró en Moscú en 1928). Sin embargo, la apertura de los archivos soviéticos muestra que la participación comunista en la iniciativa de celebrar las olimpiadas antifascistas fue más grande que lo que se tiende a pensar..$^{13}$

Lluís Companys, Presidente de la Generalitat, fue en gran medida el espíritu vivificador detrás del comité organizador de la Olimpiada Popular y su presidente honorífico. Lideraba la Esquerra Republicana de Catalunya, un partido de izquierda moderada que se había convertido en la fuerza política dominante en el gobierno autónomo regional desde su fundación en 1931 y cuya composición y objetivos eran en muchos sentidos similares a los del Frente Popular, desde antes que la URSS comenzara a promover la idea del frente antifascista de izquierda.

El esfuerzo organizativo era inmenso. A diferencia de los Juegos Olímpicos de Berlín, cuyos preparativos duraron varios años, en Barce-

\footnotetext{
11 Stout, 2016, cap. 7.

12 Stout, 2016, cap. 5.

13 Gounot, 2005, pp. 115-123.
} 
lona lograron organizarse para una competición de una envergadura similar en cuestión de pocas semanas (el comité organizador fue constituido a finales de abril de 1936), llegando el grueso de la financiación de cuatro fuentes principales: el gobierno francés (600.000 francos), ${ }^{14}$ y una suma similar aportada entre el gobierno español (300.000 pesetas) ${ }^{15}$ la Generalitat (100.000 pesetas) y la alcaldía de Barcelona. ${ }^{16}$ Los deportistas iban a competir en 16 disciplinas, entre ellas fútbol, tenis, baloncesto, boxeo, atletismo, lucha, el juego tradicional de pelota vasca, rugby y ajedrez (las tres últimas no estaban incluidas en las disciplinas reconocidas por el COI). ${ }^{17}$ Según el Trade Union Congress británico, «el objetivo es hacer frente a las consecuencias de los Juegos de Berlín mediante un festival de deporte popular que no está destinado a obtener plusmarcas, sino a mantener el espíritu olímpico de paz y cooperación entre las naciones». ${ }^{18}$

Los círculos de derecha dentro y fuera de España, naturalmente, criticaron la decisión de celebrar la Olimpiada Popular y la presentaron como un evento comunista. ${ }^{19}$ En el marco de la propaganda negativa se llegaron a esgrimir argumentos como que de hecho se trataba de una olimpiada judía internacional, que eran respaldados con «pruebas»: hubo judíos que tuvieron un papel importante en la campaña internacional para boicotear los Juegos en Berlín; a Barcelona iba a llegar una delegación de Palestina con deportistas judíos exclusivamente y una delegación de exiliados judíos europeos; el Frente Popular francés, que dio una aportación material significativa para la organización de la Olimpiada Popular, estaba encabezado por un judío, León Blum, de quien el periódico derechista La Veu de Catalunya escribió que su nombre no era «demasiado francés que digamos» y que tenía características físicas semitas muy evidentes..$^{20}$ Además,

${ }^{14}$ La Vanguardia, 15.7.1936, p. 12; Olimpiada Popular de Barcelona, Comité Organizador, Servicio de Prensa, Boletín N. ${ }^{\circ}$, p. 7.

${ }_{15}$ Mundo Deportivo, 18.6.1936.

16 Colomé, 2008, p. 15. Según Andrés Martín, el miembro comunista en el comité organizador, las contribuciones oficiales llegaron también desde Suiza. Véase: «El éxito de la Olimpiada Popular está asegurado», Mundo Obrero, 29.6.1936, p. 5.

17 Olimpiada Popular de Barcelona, Comité Organizador, Servicio de Prensa, Boletín N. 6 , p. 3 .

18 British Workers' Sports Association, «Press Information: Barcelona Popular Olympiad», Trade Union Congress, 9.6.1936, Biblioteca digital de la Universidad de Warwick.

19 «La prensa reaccionaria miente a sabiendas cuando dice que es una Olimpiada roja», Mundo Obrero, 29.6.1936. Sobre la Olimpiada Popular en la prensa contemporánea, véase Casado Hernández, 2002, pp. 627-632.

${ }^{20}$ La Veu de Catalunya, 2.7.1936. 
el presidente del comité organizador, Josep Antoni Trabal, participó en Europa en mítines de protesta por el trato discriminatorio que daba el gobierno alemán a sus ciudadanos judíos.

Pero el argumento más «demoledor» consistía en que la partitura de la Marcha de la Olimpiada de los Pueblos, himno oficial del evento, fue compuesta por Hanns Eisler, hijo de padre judío y madre luterana, que se vio forzado a exiliarse de Alemania por su origen y por sus posturas comunistas. ${ }^{21}$ Eisler se hizo famoso, entre otras cosas, por la música que había compuesto para las obras teatrales de su amigo Bertold Brecht. En manifestaciones y protestas de obreros en toda Europa era común que se entonara la «Canción de la solidaridad» de estos últimos en la primera mitad de la década de 1930. Después de la segunda guerra mundial Eisler compuso la música de la República Democrática de Alemania.

\section{Competiciones sin distinción de clase, raza o nación}

En Francia reaccionaron con entusiasmo a la iniciativa catalana. La FSGT (Fédération Sportive et Gymnique du Travail), que incluía a socialistas y comunistas que hasta poco antes habían sido enemigos acérrimos, había comenzado tiempo atrás con una campaña para «salvar los Juegos Olímpicos» que desde hacía mucho se habían convertido en «burgueses, hipócritas, chauvinistas y comerciales». ${ }^{22}$ A mediados de mayo de 1936, el periódico parisino Sport informaba a sus lectores sobre la decisión de celebrar la Olimpiada Popular en Barcelona como un mensaje alentador para todo aquel que creyera en la hermandad humana y deseara un mundo mejor. Los círculos de izquierdas en Francia y España vieron este acontecimiento como una oportunidad para estrechar los lazos entre los dos gobiernos del Frente Popular. Por ello, no debe sorprender que Léo Lagrange, subsecretario de deportes del gobierno francés, se comprometiese ante los lectores del diario comunista L'Humanité a hacer todo cuanto pudiera para que en esos Juegos participase la mayor cantidad posible de deportistas franceses. ${ }^{23}$

22 Citado en Stephan Edelsohn y Armel Goutier, «La Olimpiada olvidada», Haaretz, 31.7.1992.

${ }^{23}$ L'Humanité, 7.7.1936.
}

${ }^{21}$ Olimpiada Popular de Barcelona, Comité Organizador, Servicio de Prensa, Boletín 
Efectivamente, la francesa fue la más grande de las 23 delegaciones que llegaron a Barcelona e incluía a 1300 deportistas y acompañantes. Si tomamos el total de participantes, 6000 personas, considerando que la mitad pertenecían a las delegaciones de España, Galicia, País Vasco y Cataluña, casi la mitad de los extranjeros eran franceses. ${ }^{24} \mathrm{El}$ gran número de inscritos forzó al comité organizador a prolongar la Olimpiada Popular. La apertura original, programada para el 22 de julio, fue adelantada al 19 de ese mismo mes. ${ }^{25}$

A pesar de que el órgano del Partido Comunista Español manifestó su esperanza de que la Unión Soviética participara en los Juegos barceloneses y destacara la política deportiva y la superioridad de los atletas de aquel país, ${ }^{26}$ es interesante señalar que la URSS no envió ninguna delegación. La expectativa de algunos miembros del comité organizador de recibir a más de un centenar de competidores por primera vez en Europa Occidental para demostrar los logros soviéticos en diversas disciplinas, se vieron frustradas. El gobierno catalán no tenía interés en proyectar una imagen demasiado «roja» de las Olimpiadas Populares y seguramente no lamentó demasiado esta abstención.

Jaume Miravitlles era un ex militante comunista que en 1934 se sumó a Esquerra Republicana de Catalunya y ocuparía el cargo de vicepresidente del comité organizador; con el estallido de la guerra civil pasó a servir como secretario general de la comisión de las milicias antifascistas. Años después reconoció que una de las tareas que le había encomendado el Presidente Companys era la de impedir que el comunismo soviético explotase para sus fines políticos la celebración de los Juegos en Barcelona. ${ }^{27}$ Cabe cuestionarse si la ausencia rusa se debió a que los soviéticos no querían proyectar su sombra sobre el gobierno catalán o si fue una expresión de la política de Stalin, quien prefería cultivar los intereses diplomáticos por encima de las expresiones de solidaridad internacional. La vacilación del líder soviético al comienzo de la Guerra Civil en España hasta

${ }^{24}$ Murray, 1992, pp. 29-49; Steinberg, 1980, pp. 1-6. Entre las delegaciones hubo 12 atletas de los Estados Unidos, de los que la mitad, según se enfatizaba en las publicaciones del Comité Organizador, eran negros y también seis representantes canadienses. Véase: A.S. Lipschitz to Walter Citrine (TUC), 1.7.1936, Biblioteca digital de la Universidad de Warwick; Kidd, 1978, pp. 20-40, Kidd, 1980, pp. 1-18.

${ }_{25}$ Olimpiada Popular de Barcelona, Comité Organizador, Servicio de Prensa, Boletín N. ${ }^{\circ} 6$, p. 8 .

26 «El éxito de la Olimpiada Popular está asegurado», Mundo Obrero, 29.6.1936, p. 5.

27 Pacuet \& Pujol, 2007, pp. 42-43. 
que se decidió a enviar ayuda a la República puede indicar que la segunda hipótesis es la más razonable. ${ }^{28}$ Desde 1935 la URSS se esforzaba por integrarse en el marco del deporte internacional y comenzaba a cimentar sus lazos con organismos internacionales como la FIFA y el COI. Es probable que Moscú eligiera no poner en riesgo estas maniobras mediante su participación en la Olimpiada Popular de Barcelona.

La bandera de la Olimpiada exhibía tres figuras en rojo, blanco amarillento y negro, que sostenían juntas el estandarte de los Juegos y simbolizaban la fraternidad y la igualdad entre hombres y mujeres, blancos, negros y mestizos. Con esta imagen se debía simbolizar el enfoque integrador de la iniciativa, sin distinción de clase, raza o nación. En uno de los posters de la Olimpiada Popular, selecciones en un concurso internacional, destaca particularmente la presencia de mujeres; y efectivamente al Club Femenino y de Deporte de Barcelona le cupo un papel preponderante en la organización. ${ }^{29}$ La inclusión de atletas de color en el material visual distribuido también tenía como meta transmitir el mensaje de unos Juegos Olímpicos heterogéneos y progresistas basados en la tolerancia, en un mundo que se convertía en amenazante y polarizado entre el comunismo y el fascismo. ${ }^{30} \mathrm{El}$ objetivo era agrupar no solamente a deportistas de elite que intentasen establecer nuevas plusmarcas, sino también crear una vivencia común y aglutinante de aficionados a los deportes y a la actividad física de todos los rincones y de todos los estratos. ${ }^{31}$

\section{Palestina-Eretz Israel y las protestas contra los Juegos Olímpicos en Berlín}

También en el extremo oriental del Mediterráneo la decisión de celebrar una contra-olimpiada en Barcelona despertó gran interés, en el que se aglutinaban criterios de política local e internacional. La prensa hebrea

\footnotetext{
28 Payne, 2004; Kowalsky, 2004.

29 Olimpiada Popular de Barcelona, Comité Organizador, Servicio de Prensa, Boletín N. ${ }^{\circ}$ 6, p.7.

30 «El día pro Olimpiada Popular se celebrará el próximo día 3 y constituirá el máximo impulso a la campaña de preparación y propaganda», Mundo Obrero, 1.6.936, p. 5.

31 Olimpiada Popular de Barcelona, Comité Organizador, Servicio de Prensa, Boletín N. ${ }^{o}$ 7, p. 1; British Workers' Sports Association, Press Information, 15.6.1936, Biblioteca digital de la Universidad de Warwick.
} 
publicó no pocas noticias sobre la campaña internacional contra los Juegos en Alemania. Por ejemplo, en abril de 1936 apareció en Doar Hayom una nota bajo el título «Exigen boicotear la Olimpiada en Yugoslavia», donde decía:

Inmensa impresión provocó aquí el artículo principal publicado en el periódico más importante y más grande, Politika, contra la participación en la Olimpiada en Berlín. El artículo, en forma de una solicitud firmada por 100 personalidades de renombre en Yugoslavia y en el que rezaba que «bien sabemos que el objetivo de la Olimpiada berlinesa es comercial bélico y no es posible que aportemos nuestro dinero a la industria alemana de los cañones». Seguidamente el diario señala que el objetivo del deporte es lograr la fraternidad y la paz entre los pueblos y Alemania es actualmente un país europeo que persigue cruelmente no sólo a los judíos sino también a todas las razas «inferiores», a todos los «no arios». ${ }^{32}$

La nota finalizaba expresando la esperanza de que la solicitud, que fue publicada en periódicos adicionales, «no quede como una voz clamando en el desierto». En el matutino Davar, órgano de la Histadrut (Federación de los Trabajadores de Eretz Israel), se enfatizaba el lazo entre deporte y política, «nos guste o no... y precisamente por ello, no nos resulta igual dónde se centrarán los torneos y bajo qué régimen. Por eso tiene razón el público ilustrado y progresista que elevó su voz contra la celebración de los Juegos Olímpicos en la Alemania de Hitler y Goebbels. No se trata de un asunto de deportistas exclusivamente, sino de toda la humanidad progresista». 33

A finales de mayo, los periódicos hebreos de Palestina informaban de que el comité de los trabajadores judíos en Estados Unidos había resuelto apoyar al movimiento obrero en varios países europeos para realizar una olimpiada deportiva especial de todos los proletarios del mundo en los Países Bajos o en Bélgica como protesta contra los JJ.OO. en Berlín. ${ }^{34}$ A fin de cuentas, el Jewish Labor Committee había organizado a través del Amateur Athletic Union, un encuentro multitudinario en Nueva York, los días 15 y 16 de agosto, o sea paralelamente a los dos últimos días de los

32 Doar Hayom, «Exigen boicotear la Olimpiada en Yugoslavia», 17.4.1936, p. 11.

33 Davar, «Olimpiada, deporte y política», 23.6.1936, p. 9.

${ }_{34}$ Doar Hayom, «Olimpiada vs. Olimpiada», 29.5.1936, p. 3; Davar, «Olimpiada antinazi», 1.6.1936, p. 6 . 
Juegos de Berlín. Este Carnaval Atlético de Trabajadores del Mundo fue su forma de resistencia y protesta tanto contra la celebración del evento en la Alemania nazi como contra la participación de los Estados Unidos en esas competiciones. ${ }^{35}$

Por eso, la resolución del gobierno de Cataluña fue recibida con beneplácito en la prensa hebrea. Davar publicó varias notas al respecto:

Mientras en Berlín deliberarán los buscadores de récords de los pueblos, en Barcelona se reunirán en una olimpiada masas de deportistas populares de Cataluña y de España, de Suiza, la República Checa, Países Bajos, Rusia Soviética, etc. En el prefacio al programa de este evento internacional escriben «en la Olimpiada de Berlín primará el espíritu del nazismo, la esclavización y el odio racial, mientras que en la Olimpiada en Barcelona primará el espíritu olímpico puro, el que iguala a una raza con otra raza y a una nación con otra nación y que aspira a educar a la juventud de todas las nacionalidades en una atmósfera de paz y amistad». .6

En los días siguientes, los periódicos de Palestina ya apodaban a los Juegos en Barcelona como «la Olimpiada ideal». ${ }^{37}$

La federación deportiva Hapoel (vinculada a la federación de los trabajadores judíos) tenía claro que debía organizar una delegación para estos Juegos. En 1931, una delegación de Hapoel había participado en los torneos deportivos obreros que se celebraron en Viena y nuevamente lo hizo en 1934, siendo Praga la sede en esta ocasión. Ahora había una caracterización especial por el trasfondo de la campaña internacional de boicot a Berlín y el deseo de organizar una alternativa de izquierda a «la olimpiada nazi». También las circunstancias locales y los enfrentamientos violentos entre el movimiento nacional palestino en formación y el movimiento sionista alentaron la voluntad de presentar la posición del sionismo socialista en foros internacionales. Sumemos a ello el deseo de irritar al Comité Olímpico de Palestina y a los directivos del movimiento Maccabi, rivales acérrimos de Hapoel en la lucha por la primacía en el campo deportivo sionista, que deliberaron largamente sobre la posibilidad de enviar una delegación a los Juegos en Berlín e impidieron la participa-

35 Shapiro, 1985, pp. 255-273.

36 Davar, «El espíritu olímpico vs. el espíritu fascista en el deporte», 1.6.1936, p. 3.

37 Davar, «Olimpiada ideal», 14.6.1936, p. 2; Doar Hayom, «En las dispersiones de Israel», 9.6.1936, p. 7 . 
ción de los clubes de Hapoel en los II Juegos Macabeos que se habían realizado en abril de 1935. ${ }^{38}$

Maccabi Eretz Israel había sido fundado ya en 1912 y se consideraba como un movimiento sin distinción de clases, al servicio de la nación hebrea en formación y en el espíritu del «judaísmo muscular» de Max Nordau. Hapoel fue creado en 1926, por las olas migratorias que incrementaban el número de obreros judíos en Palestina y alentado por la constitución de la Histadrut, que además de la reivindicación sindical bregaba por proponer a los trabajadores una variedad de instituciones sociales y culturales. Maccabi se adhirió al movimiento olímpico y a las diversas organizaciones deportivas internacionales, mientras que Hapoel se integró en el movimiento deportivo obrero, que había surgido en Alemania a fines del siglo XIX y que aspiraba a contribuir al desarrollo y al fortalecimiento de la cultura en una clase obrera orgullosa y segura de sí misma. Simultáneamente fue un intento de uso del deporte para reclutar apoyo y para protestar por la discriminación que impedía a la clase obrera acceder a diversas prácticas deportivas. Esa razón llevó a la creación de clubes deportivos obreros, federaciones de diversas disciplinas y la organización de torneos que daban a los trabajadores la oportunidad de participar en actividades físicas sanas y festejar su poder y sus aspiraciones como clase, fuera del presunto marco chauvinista, comercial y competitivo de los «deportes burgueses»..${ }^{39}$

A raíz de esto, Hapoel se adhirió como miembro de la SWSI (Internacional Deportiva de los Trabajadores Socialistas), una organización creada en 1921. Ese mismo año se celebraron en Praga los I Juegos Internacionales de Deportes Obreros. Los I Juegos Olímpicos de los Trabajadores se realizaron en 1925 en Fránkfurt, con la participación de representantes de 19 países y atrayendo la presencia de más de 150.000 espectadores. ${ }^{40}$ Los II Juegos Olímpicos de los Trabajadores tuvieron lugar en Viena en 1931, con cerca de 80.000 trabajadores-competidores de 26 países y un público que se estimó en 250.000 personas. ${ }^{41}$ La participación de mujeres fue central en estos Juegos, con unas 25.000 participantes en Viena, si lo comparamos con las 107 mujeres

38 Davar, «'Hapoel'sobre la cancelación de su participación en la Macabiada», 31.3.1935; Kaufman, 2007, pp. 554-565.

39 Kidd, 2013, pp. 503-514.

40 Steinberg, 1978, pp. 233-251.

41 Wheeler, 1978, pp. 191-210. 
que competirían en los Juegos Olímpicos de Los Ángeles un año después. Los comunistas tenían también sus Espartaquiadas. La llegada de los nazis al poder y la represión contra los partidos de izquierda y los sindicatos en Alemania llevó a socialistas y comunistas a cooperar para promover la Olimpiada Popular de Barcelona.

El 22 de junio de 1934 se enviaba desde Berlín una invitación oficial al Comité Olímpico de Palestina, que había obtenido el reconocimiento del COI aproximadamente un mes antes, para participar en los Juegos Olímpicos de verano de 1936. Los miembros del Comité hebreo se enfrentaban a un gran dilema: responder afirmativamente podía dar por tierra con los esfuerzos del boicot internacional y un rechazo podía dañar el estatus internacional del comité, a los deportistas judíos en Alemania y en otros países que iban a participar en los JJ.OO.. La organización Maccabi en Alemania incluso se dirigió al comité en Palestina, probablemente bajo presión de las autoridades del Reich, solicitando que no boicoteara los Juegos. Finalmente este comité resolvió no participar, pero la negativa fue redactada de forma diplomática. El presidente del comité, el coronel Frederic Hermann Kisch, envió una carta a los organizadores en Berlín explicando que, por tratarse de una institución que estaba en sus primeras etapas de organización, no podría aún enviar deportistas a las competiciones en Alemania. ${ }^{42}$

Esta respuesta formal causó incomodidad en diversos círculos. Para la gente de Hapoel, los de Maccabi eran capitalistas burgueses que rehuían la resistencia activa contra el fascismo, el antisemitismo y la tiranía, mientras que ellos, los representantes del deporte obrero, asumían el reto y se unían a la Olimpiada Popular en Barcelona. Poco antes de partir hacia la ciudad condal, Israel Carmi, uno de los miembros de mayor jerarquía en la delegación de Hapoel, redactó el «Manifiesto de Hapoel para la Olimpiada antinazi de Barcelona»:

¡Saludos a los trabajadores libres de España! Mientras que sobre esta Olimpiada flamean las banderas de la libertad, en la Alemania nazi se está llevando a cabo la Olimpiada que simboliza la esclavitud, la represión y el despotismo. ¡Viva nuestra Olimpiada! Que salga de esta Olimpiada un llamado entusiasta a los trabajadores del mundo para unir fuerzas en la guerra contra la guerra y por la realización del socialismo.

${ }^{42}$ Harif, 2011, cap. 5. 
¡Hermanos y camaradas! Nuestro pequeño país, que estuvo yermo durante dos mil años, renace desde que comenzamos a retornar a él. Hemos vuelto a nuestra patria destruida por el deseo sincero de construir junto con los trabajadores árabes una patria libre para los hijos de ambos pueblos... Desde hace tres meses que un terrorismo cruel [árabe] impera en el país, se ensaña con niños y mujeres [judíos] y sin embargo nuestros jóvenes, musculosos y experimentados combatientes, han sabido evitar la venganza y no derramar sangre inocente.

Desde aquí, desde la tarima de la Olimpiada, declaramos a todos los pueblos y a los trabajadores del mundo entero: nuestro propósito es trabajar y vivir en paz con el pueblo árabe. Y para finalizar: ¡Viva la Olimpiada antinazi! ¡Viva la libertad! ¡Viva la fraternidad entre los pueblos! ¡Viva el socialismo! ¡Viva España libre! ¡Viva la resurrección del trabajador en Eretz Israel! ${ }^{43}$

\section{Hapoel y la delegación de los deportistas de Palestina}

La dirección central de Hapoel formó una delegación que incluía una serie de destacados deportistas ${ }^{44} \mathrm{El}$ documento en que se pormenoriza «la cuenta de arreglos de los viajes de la delegación a la Olimpiada (en Barcelona)» incluye los nombres de 21 atletas a los que se les debía sufragar los costes de obtención de un visado (francés para uno, inglés para otros dos), renovación del pasaporte de cuatro de los participantes y pago por el regreso al país de uno. El resto de los gastos debían ser cubiertos supuestamente por los anfitriones catalanes. ${ }^{45}$ Entre los selecciones destacaban los futbolistas, sobre todo de Hapoel Tel Aviv y de Hapoel Haifa. Zalman Friedman (nacido en 1912) era el mediocampista ofensivo (volante con llegada) de Hapoel Tel Aviv en las décadas de 1930 y 1940 . Con esa escuadra obtuvo los campeonatos de la primera división y las Copas de Israel en 1934, 1935, 1938 y 1940. También lució la camiseta de la selección de Palestina y de la selección de Hapoel para las olimpiadas obreras jugadas en Viena y Praga. Abraham Nudel-

43 Yahav, 2008, p. 214. En un espíritu similar escribió también el boletín del movimiento juvenil sionista socialista Hashomer Hatzair: «Hapoel en la Olimpiada anti-fascista en Barcelona», Hashomer Hatzair, N. . 14, 1936, pp. 14-15.

44 Sport Haboker, 5.7.1936, p. 4.

45 «Para la Convención de Hapoel», 11.7.1936, Archivo Lavón de Historia del Partido Laborista Haavodá, IV, pp. 244-55. 
man (nacido en 1910) fue extremo lateral (alero, delantero izquierdo) del mismo equipo en Tel Aviv cuando conquistó la copa por primera vez en 1928, en gran medida gracias a un gol del propio Nudelman. El poeta hebreo Alexander Penn, de militancia comunista y ex boxeador en Hapoel Tel Aviv, inmortalizó su nombre en unos versos dedicados al club de Hapoel Tel Aviv que fueron publicados en Davar en marzo de 1932.

Abraham Beit-Halevy (nacido en 1913) había llegado a Palestina desde Polonia con sus padres, en 1920. Defensa de Hapoel Tel Aviv, trabajaba también como intérprete en el ejército británico. Gdaliahu Fuks (nacido en Transilvania en 1911) comenzó a practicar el futbol a los 15 años, en las divisiones juveniles del club judío Shimshon, pese a la oposición de sus padres. En 1929 fue con el equipo adulto a jugar a Checoslovaquia, sin la autorización de sus padres, que le castigaron apartándolo de la familia. Se mudó entonces a Czernowitz, donde jugó en las filas del Hakoah local. En 1931 emigró a Palestina invitado por su hermano Shlomó, que jugaba a la sazón como centrocampista en Hapoel Haifa. Gdaliahu ocupó el puesto de su hermano, que se había retirado, y en poco tiempo se convirtió en uno de los jugadores más destacados y el primer capitán de la selección de Palestina. Lideró al combinado en el marco de las preliminares para los mundiales que se disputaron en Italia en 1934 y en Francia en 1938. Como jugador de Hapoel también participó en las olimpiadas obreras y aprovechó la oportunidad para reencontrarse con su familia y hacer las paces. Yehoshua (Shuka) Brashedsky nació en Haifa en 1914 y era un destacado delantero centro de Hapoel Tel Aviv a mediados de la década de 1930, y transferido en 1938 a Hapoel Haifa, y también jugó en la selección palestina. Yaakov Breuer y Yona Stern también formaron parte de la delegación. Stern era algo mayor que sus compañeros, nacido en Klausenburg o Cluz, Transilvania, en 1908. Desde muy joven jugaba al fútbol y en 1922 se mudó a Austria, donde pasó a formar parte del prestigioso Hakoah Viena. En 1925, cuando Hakoah Viena estaba de gira en Palestina, Stern decidió quedarse y pasó a jugar en Hapoel Haifa, que había sido fundado apenas un año antes. Dos años más tarde regresó a Hakoah Viena, donde alcanzó gran éxito. A finales de 1930 volvió a Hapoel Haifa y en 1933 fue a Francia, donde jugó para Stella Paris y para Saint Etienne. Una vez más regresó a Haifa y la selección palestina y a los partidos disputados en las eliminatorias para la copa del mundo.

La comisión organizadora barcelonesa recibió con satisfacción la noticia de la llegada del equipo de fútbol de Palestina, que debía competir con 
otros 15 rivales. ${ }^{46}$ El servicio de prensa de la Olimpiada Popular enfatizó la calidad de la formación: «Cabe especialmente destacar la participación de una selección de primer nivel que llegará del club deportivo Hapoel en Palestina. Es una selección que se ha medido recientemente con un equipo de elite húngaro y empató 2:2. Su entrenador es el famoso austriaco $\mathrm{Ne}-$ mes Neufeld». ${ }^{47}$

Efectivamente, Sándor Nemes, cuyo nombre original era Alexader Neufeld, fue un jugador húngaro-judío y un entrenador de renombre en su tiempo. Nacido en 1899, su larga y ramificada carrera incluyó su paso por Hungría, Austria, Suiza, Estados Unidos y Yugoslavia. Había jugado en las selecciones nacionales de Hungría y de Austria. En este último país lució la camiseta de Hakoah Viena; en la temporada de 1924 ganó con dicho club el campeonato de la liga austríaca y la copa europea tras derrotar al Westham United 5:0, en un partido en el que Nemes marcó tres goles. Jugó asimismo un tiempo breve en Checoslovaquia, en Maccabi Brno. En la década de 1930 fue entrenador de diversos equipos europeos y en 1935-36 lo fue de Hapoel Haifa durante algunos meses. Regresó a Israel en 1950 como entrenador de Hapoel Tel Aviv.

Pese a la centralidad del fútbol, la delegación a Barcelona incluía atletas de otras disciplinas. ${ }^{48}$ Destacaban entre ellos el luchador Nickolaus (Mickey) Hirschl, nacido en Viena en 1908 y miembro del club Hakoah de su ciudad natal, al que representó conquistando el campeonato de Austria en diez oportunidades, campeón europeo y medallista de bronce en peso pesado en los Juegos Olímpicos de Los Ángeles en 1932, tanto en lucha libre como en greco-romana (Hirschl estaba desde hacía poco tiempo en Palestina), el boxeador peso mosca Bill Birinbaum, que había sido campeón de Varsovia, un boxeador de apellido Laub, peso pesado y ex campeón de Austria, y Rachel Ozik, que competía en salto de altura.

Pero la participante de mayor jerarquía en la delegación era Sonja Lewin-Szmukler, la más importante de las atletas de Palestina. Oriunda de

46 Ya a comienzos de junio informaba el boletín del Comité Organizador que «se comunicaron con la Organización Sionista Internacional en Londres, buscando obtener una participación oficial del sionismo en la Semana del Deporte Internacional en Barcelona. Las negociaciones sugieren un resultado muy favorable», Olimpiada Popular de Barcelona, Comité Organizador, Servicio de Prensa, Boletín N. ${ }^{\circ}$ 6, p. 6.

47 Olimpiada Popular de Barcelona, Comité Organizador, Servicio de Prensa, Boletín N. 7 , p. 3.

48 Pujadas \& Santacana, 2006, p. 193; Olimpiada Popular de Barcelona, Comité Organizador, Servicio de Prensa, Boletín N. 7, p. 4. 
Polonia, comenzó su actividad deportiva en Maccabi Vilnius y destacó en el lanzamiento de peso, disco y martillo. En el campeonato polaco de atletismo de 1930 obtuvo la medalla de oro en lanzamiento de peso y llegó al décimo puesto del ranking mundial. En la segunda Macabiada, celebrada en 1935, Lewin obtuvo la medalla de plata, detrás de Lilian Copeland, la campeona olímpica estadounidense. Después de esa competición se afincó en Palestina con su familia. ${ }^{49}$

La segunda Macabiada, que también puede ser vista como una manifestación de protesta por la discriminación de deportistas judíos en Alemania, fue la «Macabiada de la migración a la Tierra de Israel». Participaron 1350 deportistas de 28 países, entre ellos una delegación alemana que había sido autorizada por el gobierno nazi. Dado que el gobierno mandatorio británico continuaba restringiendo los visados que se concedían para inmigrantes, muchos de los participantes en los Juegos Macabeos, particularmente de las delegaciones de Bulgaria, Alemania y Polonia, aprovecharon la oportunidad para establecerse en el país después de terminada la competición deportiva.

En una entrevista concedida en vísperas de la apertura de la Olimpiada Popular al diario comunista español Mundo Obrero, Chaim Glowinsky, uno de los directivos de la delegación de Hapoel, manifestaba su orgullo por la composición y la calidad de los delegados, varios de ellos campeones europeos, y que en virtud de su migración a Palestina representaban ahora el deporte de los trabajadores judíos. Glowinsky mencionaba particularmente los éxitos de Rachel Ozik en salto de altura y de Sonja Lewin en lanzamiento de peso y de disco. ${ }^{50}$

\section{EI largo camino a Barcelona}

El 16 de julio, muchos atletas de la numerosa delegación francesa, ${ }^{51}$ abordaban el tren que les transportaría a Barcelona y que era acompa-

49 En 1937 conquistó la plusmarca de Palestina-Eretz Israel en lanzamiento de bala, récord que mantuvo durante 22 años. Véase Davar, «Atletas y plusmarcas en el deporte», 8.2.1952.

50 «Opiniones de tres delegados internacionales sobre la Olimpiada», Mundo Obrero, 18.7.1936, p. 5.

51 «Deportistas franceses constituirán la más fuerte delegación extranjera en la Olimpiada Popular», Mundo Obrero, 18.7.1936, p. 6. 
ñado por una multitud que se acercaba a despedirse de los deportistas en la estación. ${ }^{52}$ Para su desilusión, fueron pocos quienes vinieron a recibirlos al día siguiente en su destino. Los franceses se alojaron en el hotel Olímpico, en Plaça de Espanya, donde se encontraron con grandes salas en las que se habían esparcido numerosos colchones. Por falta de tiempo y de presupuesto, en la ciudad no se había podido construir una villa olímpica y los miles de deportistas que acudieron tuvieron que pernoctar en albergues populares que parecían más bien dormitorios obreros, de a cuatro u ocho por cuarto, y en apartamentos esparcidos por la ciudad..$^{53}$ Debido a esto, los atletas se encontraban junto a la población local y no apartados en un espacio acotado, lo que les permitía sentir el pulso urbano.

El trayecto de los deportistas de Palestina fue mucho más agotador que el de los franceses: zarpando desde el puerto de Haifa, vía Argelia y Túnez, hasta Marsella, de allí por tren hasta la población fronteriza de Portbou en los Pirineos, para continuar luego hasta Barcelona. Dos semanas antes viajó Chaim Glowinsky, quien compartía con Carmi el Liderazgo de la delegación, para ocuparse de los preparativos. Glowinsky fue uno de los más importantes dirigentes del deporte en la Palestina judía y posteriormente en el Estado de Israel.$^{54}$ Había sido uno de los fundadores de Hapoel. Los miembros de la delegación esperaban en Haifa su señal desde Cataluña indicando que todo estaba bien y que podían embarcarse a bordo del Patria e iniciar el periplo.

El sábado 18 de julio al anochecer en Barcelona comenzaron a reunirse en el estadio, en la parte superior de Montjuic, numerosos deportistas que querían ver el lugar en el que iban a competir y de paso relacionarse con sus colegas llegados de diversas latitudes. Algunos atletas intentaron entrenarse antes de la inauguración. No fueron pocos los organizadores que decidieron permanecer y dormir en el lugar. Pau (Pablo) Casals, violonchelista y compositor, hizo un ensayo general con su orquesta de Barcelona, de la que era director, interpretando una vez más la novena sinfonía de Beethoven antes de la ceremonia de apertura, que debía tener lugar al día siguiente en el Teatro Griego de Montjuic (lo ha-

52 «Un tren especial desde París», Mundo Deportivo, 6.7.1936; Ha'aretz, 31.7.1992.

53 «Los atletas noruegos en la Olimpiada Popular. Enorme pedido de alojamientos en Barcelona», Mundo Obrero, 11.7.1936, p. 5; Olimpiada Popular de Barcelona, Comité Organizador, Servicio de Prensa, Boletín N. 7 , pp. 5-6.

${ }^{54}$ Paz \& Zimri, 1982. 
bía hecho cinco años antes, al establecerse la Segunda República). El concierto festivo no llegó a celebrarse y Casals no volvió a dirigir ni a tocar en suelo español.

La Olimpiada Popular pretendía presentar una alternativa en lo que se refiere a la participación basada en la identidad nacional. Representantes de países que se encontraban bajo un gobierno colonial participaron como delegados de países soberanos, en igualdad de condiciones con países veteranos. Tal fue el caso de Palestina, que se encontraba bajo mandato británico, o de Marruecos, donde la mayor parte de su territorio estaba aún dominado por los franceses y una parte del norte en manos de España. ${ }^{55}$ También exiliados judíos de la Alemania nazi y exiliados anti-fascistas obtuvieron su participación en las competiciones, junto a delegaciones regionales de Alsacia y Lorena, del País Vasco, Galicia y Cataluña. ${ }^{56} \mathrm{La}$ predisposición a reconocer una multiplicidad de identidades quedó en evidencia también al incluir un equipo de fútbol femenino de Estudiantes del Mundo.

Los huéspedes del hotel Olímpico despertaron en medio de la noche por ruidos de explosiones. Por la mañana comenzó a aclararse que se trataba de un intento de rebelión de una parte del ejército español. Varios de los soldados del batallón apostado en Barcelona abandonaron su cuartel para participar en este pronunciamiento, obedeciendo a las instrucciones recibidas desde el comando en Pamplona, al mando del general Emilio Mola, uno de los líderes del levantamiento. Se prohibió a los visitantes salir del hotel, mientras milicianos anarquistas tomaban posiciones detrás de barricadas ${ }^{57}$ Tony Binet, corredor de fondo y boxeador, fue uno de los delegados británicos que ya había participado en eventos internacionales de deporte obrero. ${ }^{58}$ La selección de cincuenta atletas llegó desde el Reino

55 Mundo Deportivo, 7.6.1936.

${ }^{56}$ En una carta dirigida a Sir Walter Citrine, secretario del Congreso de los Sindicatos de Gran Bretaña (Trade Union Congress), los organizadores destacaban que «de particular interés para los anti-fascistas son los deportistas judíos que vienen de Palestina, los equipos de judíos alemanes exiliados de París y Ámsterdam y los deportistas negros de los Estados Unidos», Olimpiada Popular de Barcelona, Comité Organizador a Citrine, 12.6.1936, Biblioteca digital de la Universidad de Warwick.

57 Sobre los testimonios de los representantes británicos, véase: Walters, 2006, cap. 6; Jones, 1988, pp. 185-186.

${ }^{58}$ Sobre la delegación británica, véase: British Workers' Sports Association, Organizing Committee for Team for Barcelona Peoples' Olympiad, Press Information, 24.6.1936, Biblioteca digital de la Universidad de Warwick. 
Unido a Barcelona tras un viaje de 57 horas en tren. El testimonio de Binet es muy similar al de sus colegas franceses:

Me desperté muy temprano por la mañana con lo que pensé que eran vigorosos pelotazos... Asomándome (al balcón) veía una calle angosta desierta, exceptuando seis civiles armados, miembros de la patrulla nocturna de la Milicia Obrera. Desde el final de la calle de enfrente vi un grupo de hombres y una mujer desde detrás de una barricada de piedras erigida en forma rápida, disparando hacia un auto que cruzaba la calle a una velocidad fatal. ${ }^{59}$

El 19 al mediodía los organizadores intentaban tranquilizar a los huéspedes. Los representantes del comité explicaron que, efectivamente, parte del ejército se había levantado contra el gobierno de la República, pero en lo tocante a Barcelona, por lo menos, no debían temer por su integridad física ya que el dominio republicano en la ciudad era estable. Pero parecía que les costaba tranquilizarse ellos mismos, mientras que los visitantes comprendían que estaba ocurriendo algo importante y que las competiciones deportivas no comenzarían ese día como estaba programado. En las calles se veían escaparates destrozados, varios vehículos incendiados y varios edificios destruidos. Algunos deportistas fueron rápidamente a las oficinas de correo más cercanas para telegrafiar a familiares y amigos y tranquilizarles, explicando que sus vidas no corrían peligro.

Los deportistas provenientes de Palestina llegaron al lado español de los Pirineos el día 20 y desde allí debían continuar en tren hasta Barcelona. Israel Carmi lo relataba así:

En Portbou había un túnel gigantesco por el que debía pasar el tren. Los soldados que controlaban la zona nos dijeron que no había paso. Sólo entonces supimos que la noche anterior a nuestra llegada a España estalló la Guerra Civil y que el general Franco intentaba asumir el control del país. Nos dijeron que el camino a Barcelona estaba bloqueado por los fascistas y que en toda España se estaban librando cruentas batallas. Escuchamos la radio para saber qué ocurría. Entonces llegó el anuncio: «Esta es la estación principal del Comando de la República Española desde Barcelona. El general Franco inició una guerra contra el pueblo de la España libre». Al final de los anuncios de cuestiones de se-

59 Citado en Martin, 1992, pp. 6-8. 
guridad, el locutor dijo que el Comité Organizador de la Olimpiada popular informaba que dada la situación de la seguridad, la inauguración de los Juegos Olímpicos se postergaba hasta nuevo aviso.

Mientras tanto, llegó a la estación del ferrocarril un auto militar con un representante de la comisión militar republicana, con una solicitud al jefe de la delegación de Hapoel de acudir de inmediato para consultas. Informé a todos los miembros de la delegación que debían quedarse en sus sitios en el vagón. En la comandancia local se encontraba también el alcalde. Dijo que haría todo para ayudarnos, pues estábamos varados sin comida, sin lugar para pernoctar y sin medios. Pedí permiso para que nuestros deportistas siguieran viviendo en los vagones que los trajeron y que me otorgasen un pase especial para poder llegar a Barcelona. Pedí al alcalde, si podían, que organizaran para nuestros deportistas un partido de entrenamiento contra un combinado local y quizás también que les sacaran a excursiones por los alrededores. ${ }^{60}$

Carmi dio instrucciones a los delegados sobre cómo actuar en su ausencia y nombró una comisión de tres personas (tesorero, ecónomo y encargado de seguridad) y les confió la responsabilidad sobre los deportistas y su bienestar.

Antes de salir de Portbou, escuché en la radio anuncios a las diversas delegaciones deportivas y entre otras escuché la voz de nuestro compañero Glowinsky en hebreo: «Bienvenidos, estoy en Barcelona ocupándome de los asuntos vinculados a vuestra situación. Espero aquí a Carmi». Por la tarde llegó nuestro taxi, el blindado. Nos presentamos con los periodistas que viajaban conmigo y con el conductor. Pronuncié la plegaria de agradecimiento para quien ha salido de una situación en que peligra su vida y partimos. En el camino nos detuvieron soldados republicanos, que nos previnieron sobre francotiradores fascistas que disparaban contra automóviles en la carretera principal. Cogimos un camino secundario, y pese a ello fuimos atacados con una ráfaga de disparos que, para nuestra fortuna, no penetró. Pensé entonces que se acababa la vida. Más adelante aparecieron unos faroles rojos con la leyenda «ALTO». A una distancia de decenas de metros oímos intercambio de disparos y paquetes de gran tamaño volando por el aire desde el techo de una iglesia y una multitud de lugareños y de los alrededores gritando « $i$ Viva la República!» y un canto a voz en grito. Los soldados

${ }^{60}$ Yahav, 2008, p. 214-215. 
que estaban allí nos contaron que en la iglesia habían encontrado a una escuadrilla de franquistas y la multitud los liquidó lanzándolos desde el techo de la iglesia, aproximadamente unos cuatro pisos [de altura]. ${ }^{61}$

El trayecto de Portbou a Barcelona en tren, de unos 200 km, debía cubrirse en unas 3 horas, pero se alargó desde las tres de la tarde hasta el mediodía del día siguiente. Incluyó muchas demoras puesto que los pasajeros despertaban sospechas y desconfianza, o por tiroteos entre los bandos que apoyaban la rebelión y los defensores de la República. Para el último tramo, les asignaron dos automóviles de custodia y sobre el taxi colocaron una pancarta con la leyenda que se trataba de extranjeros que iban a la Olimpiada en Barcelona. ${ }^{62}$ Carmi, los dos periodistas y el conductor local encontraron finalmente la forma de llegar a Plaça de Catalunya, en pleno centro de la ciudad, donde fueron testigos del baño de sangre que había ocurrido poco antes.

El terreno en su totalidad parecía un matadero, decenas de cadáveres de soldados y de caballos esparcidos por la plaza, algunos de ellos aún con estertores. Todas las paredes parecían [perforadas como] una colmena... A medida que se avanzaba caminando había más y más cadáveres. Era terrible. Con miedo y desesperación llegamos al edificio del comité organizador de la Olimpiada y allí por fin encontré a Glowinsky. Camino al hotel, con soldados escoltándonos, oímos la estación de radio difundiendo: 'Atención, atención, barceloneses. Un auto a toda velocidad con una escuadra fascista dispara a troche y moche'. Antes que lográramos entrar al hotel vemos una muchedumbre agolpándose alrededor de un monocasco militar y junto al auto soldados republicanos prendiéndole fuego con sus ocupantes, que en un tiempo breve lograron cobrarse varias víctimas entre los peatones de la ciudad. ${ }^{63}$

La viuda de Glowinsky presentó el punto de vista de su marido, que sin buscarlo se encontró en el ojo del huracán en la capital catalana:

¡Tiene que pensar en cómo eran las cosas! Por la mañana Chaim despierta y se encuentra dentro de una revolución. No es sencillo. Sabe que la delegación quedará atascada en la frontera y la situación era más

61 Yahav, 2008, p. 215.

${ }^{62}$ Davar, «En España en los días de la insurrección: miembros de la delegación de Hapoel informan sobre hechos e impresiones», 10.8.1936, pp. 2-3.

63 Yahav, 2008, p. 215. 
compleja aún puesto que no existían en absoluto pasaportes israelíes. Cado uno [de los atletas] llevaba otro pasaporte. Durante todo aquel caos estaba completamente solo. Por cómo conocí a Chaim, él no temía a nada. Pero, por otra parte, cuando te disparan desde la izquierda y desde la derecha, no eres ningún héroe. En Palestina no sabíamos absolutamente nada de lo que estaban pasando, porque no teníamos contacto hasta que recibí un telegrama suyo que decía: «Estoy en Barcelona y controlamos la situación». Se refería a que los izquierdistas controlaban el terreno; todos esperábamos que Franco fuera derrotado. ${ }^{64}$

Según Carmi, hasta el atardecer de aquel día estuvieron quitando de la plaza todos los cadáveres que había visto al llegar y en el sitio tuvo lugar una gran manifestación de partidos de izquierda y de defensores de la República. «Por la noche, la dirección de la Olimpiada nos comunicó que no veían ninguna posibilidad de realizar el encuentro mientras durara la guerra». Aunque el 19 de julio por la mañana Jaume Miratvilles anunciaba por Radio Barcelona que la inauguración se llevaría a cabo tal como estaba planificada y que la revuelta militar había fracasado en Barcelona, la decisión fue de cancelar los Juegos.

\section{Despedida de España}

El consulado francés en Barcelona anunció a todos los deportistas llegados desde el país vecino que la armada gala enviaría dos barcos que se encontraban apostados en Argelia, para evacuarlos al puerto de Marse1la. Algunos atletas prometieron regresar y ayudar a los españoles en su lucha; otros prefirieron permanecer y movilizarse directamente para los combates. De cualquier modo, la marcha de solidaridad de todos los deportistas desde el centro de la ciudad hacia el estadio en que debían celebrarse los Juegos fue organizada de forma precipitada ${ }^{65}$ Según el testimonio de Binet:

Con nuestros gaiteros escoceses al frente, nosotros, con los equipos de todas las demás naciones representadas, marchamos en la procesión hacia el estadio deportivo escoltados por autos blindados. Marchábamos cruzando gigantescas masas de gente, masas sobre cuyas cabezas se le-

64 Ibid.

${ }^{65}$ La Vanguardia, 24.7.1936, p. 1. 
vantaba un mar de puños apretados en el saludo anti-fascista. Nunca, hasta entonces, había experimentado semejante emoción de orgullo. ${ }^{66}$

El 22 de julio llegaron los barcos franceses para recoger a los deportistas. Glowinsky y Carmi consiguieron para los delegados de Palestina billetes desde Marsella a Haifa. La región levantina del Mediterráneo, con su tormentosa lucha entre judíos, palestinos y británicos, parecía ahora un refugio seguro comparado con el infierno que se cernía sobre España. La decisión de los jefes de la delegación fue enviar de inmediato a Marsella a Carmi para que luego volviera a Portbou a buscar a los atletas judíos que se encontraban allí. Glowinsky permanecería dos días más en Barcelona, tras los cuales saldría también él en un barco hacia Marsella. ${ }^{67}$

Tres días después, Carmi llegó al lado francés de los Pirineos, pero no pudo cruzar el túnel, que estaba cerrado por razones de seguridad.

Por casualidad, encontré un grupo de voluntarios de Hungría, Polonia, Alemania y Rusia, que deseaban... luchar junto a los republicanos. Eran unos treinta, hombres y mujeres, con un guía francés... y por sugerencia de los pobladores de la aldea francesa señalaron un sendero por los montes, a aproximadamente $10 \mathrm{~km}$ de caminata de Portbou. Durante la agotadora caminata conversé con los voluntarios sobre su movilización y ellos me respondieron: «Vemos cada día cómo dos chalados, Hitler y Mussolini, conducen a Europa hacia la perdición, esto llevará a una guerra terrible, debemos detener el proceso destructor». Al cabo de unos kilómetros distinguí a un grupo de personas que venían caminando en dirección opuesta, entre ellos dos miembros de nuestra delegación. Gritamos «Shalom, shalom» en hebreo y nos abrazamos. ${ }^{68}$

Carmi contó que mientras permanecieron en Portbou, los deportistas de Palestina jugaban al fútbol con los niños de la aldea y trabaron amistad con sus padres. Lamentaron oír que los Juegos habían sido cancelados por la insurrección militar, pero al mismo tiempo se alegraron al oír que al cabo de unos días estarían de regreso en sus hogares. Cuando la locomotora francesa llegó para enganchar los dos vagones en los que la dele-

66 Citado en Martin, 1992, pp. 6-8.

67 Glowisky efectivamente viajo en un barco de guerra inglés a Marsella. Ver Davar, «En España en los días de la insurrección: miembros de la delegación de Hapoel informan sobre hechos e impresiones», 10.8.1936, pp. 2-3.

68 Yahav, 2008, p. 216. 
gación había permanecido durante una semana, los pobladores de Portbou se despidieron de ellos de modo conmovedor.

\section{Los primeros voluntarios internacionales}

Se estima que unos 200 deportistas de diversos países permanecieron en España para sumarse a la lucha en defensa de la República y salieron de forma organizada hacia el frente en Zaragoza. ${ }^{69}$ La más célebre entre ellos fue Clara Ensner-Thalmann, nacida en Basilea e hija de un socialista alemán que se refugió en Suiza durante la guerra franco-prusiana. A muy temprana edad se afilió al Partido Comunista Suizo y al cabo de unos años se mudó a Francia, donde escribía para el periódico del PCF, L'Humanité, mas a finales de la década de 1920 adoptó posturas anti-soviéticas y se acercó a círculos trotskistas tras regresar a Suiza. A Barcelona llegó como representante del club obrero de natación, el Arbeiterschwimmclubs.

Tras el estallido de la Guerra Civil se enroló en la Columna Durruti, de combatientes anarquistas, marchando al frente aragonés, donde se le sumó su marido Paul Thalmann. Perseguidos los anarquistas por los comunistas, los Thalmann intentaron salir de España y fueron detenidos. Al cabo de unos meses fueron liberados y se establecieron en París. Tal como ocurrió con no pocos brigadistas internacionales, como por ejemplo David Ostrovsky, Marcel (Mendel) Langer, y Zeev (Philip) Gotesman, que habían llegado a España después de haber residido un tiempo en $\mathrm{Pa}$ lestina, durante la Segunda Guerra Mundial participaron activamente en la Resistencia francesa. ${ }^{70}$

Israel Carmi relató en su testimonio que algunos de los miembros de la delegación de Palestina pidieron quedarse para sumarse a las filas anti-fascistas: «No permití a ninguno reclutarse. Obligué a todos a regresar conmigo a Haifa. Hay que entender que yo prometí personalmente a todas las familias que traería a los muchachos sanos y salvos. Era esta una de las condiciones para salir. Las madres me habrían demandado, y justificadamente». ${ }^{71}$

69 «Muchos de las... representaciones extranjeras de atletismo se han alistado en las milicias», La Vanguardia, 24.7.1936, p.1; Richardson, 1982, p. 24, nota 35; Wullschleger, 1939 , p. 78.

70 Ver el libro de memorias de ambos: Thalmann, 1985.

71 Yahav, 2008, p. 216. 
Entre los deportistas que llegaron desde Palestina, aunque no en el marco de Hapoel, sabemos de tres que se quedaron y combatieron en España. Chaim Elkon, que iba a participar en la Olimpiada Popular como árbitro de fútbol y después se enroló junto con un grupo de voluntarios alemanes y polacos que habían llegado desde Francia al batallón Thälmann de las Brigadas Internacionales. Este batallón llevaba el nombre del líder comunista alemán Ernst Thälmann, que encabezaba el partido durante la mayor parte del periodo de la República de Weimar, fue detenido por la Gestapo en 1933 y permaneció incomunicado durante 11 años. En agosto de 1936 Elkon moría en los combates próximos a la ciudad universitaria en Madrid. Su unidad fue rodeada por fuerzas nacionalistas y Elkon halló la muerte mientras intentaba cubrir con la metralleta que tenía a su cargo el intento de sus camaradas de armas de romper el cerco. ${ }^{72}$

Nachum Weiss llegó a los Juegos en Barcelona junto con Elkon y con Imre Jacobi. También él combatió para defender la República y murió a los pocos meses de comenzada la contienda. Weiss, que en algunas publicaciones del Partido Comunista de Palestina Israel aparece con el nombre Nachumi Weitz y en otras fuentes como Albert Nachumi, estaba en el batallón que homenajeaba la memoria de Edgar André, otro dirigente comunista alemán que estaba en prisión desde poco después que los nazis asumieran el gobierno. Weiss murió en noviembre de $1936 .^{73}$

De los tres, Jacobi era el más conocido y sobre el que tenemos más información biográfica. Imre provenía de una familia de bajos recursos, y abandonó su afición por el violín para dedicarse al fútbol, que podía asegurarle el sustento. ${ }^{74}$ El equipo en el que jugaba, Hagibor Bratislava, llegó a Palestina en 1927 para disputar una serie de partidos e Imre decidió quedarse. El comienzo de su trayectoria deportiva en el país pasó por diversos lugares: Hapoel Allenby Tel Aviv, Hapoel Haifa y Maccabi Haifa. En 1930 entró en Maccabi Tel Aviv como volante izquierdo. En 1931 jugó con la selección de Palestina en Egipto, uno de los seis jugadores judíos. Un año después jugó en las Macabiadas con la selección de Maccabi Eretz Israel.

${ }^{72}$ Kol Haam, «Recordará», 18.7.1947, p. 3; Kol Haam, «Bendita sea su memoria», 15.7.1949, p. 5; Yahav, 2008, p. 216.

73 Kol Haam, «Recordará», 18.7.1947, p. 3; Kol Haam, «Bendita sea su memoria. Hijos de Eretz Israel que han caído en combate de la guerra santa por la libertad del Hombre sobre el suelo de España», 15.7.1949, p. 5.

${ }^{74} \mathrm{Kol} \mathrm{Haam}$, «Imre Jacobi (20 años de su muerte en el frente de España)», febrero de 1957. 
Su acceso al estrellato, en los términos de la época, se produjo cuando en junio de 1933 marcó el tanto de la victoria en la final de la Copa de Palestina en el partido contra Hapoel Tel Aviv. ${ }^{75}$ «Cuando Imre circula por la calle Allenby montado en su motocicleta Norton», escribió uno de los periódicos de la época, «muchos corazones laten con fuerza». ${ }^{76} \mathrm{Una}$ familiar, Noa Jacoby-Stevenson, recuerda las historias que contaban sobre él como «un soltero empedernido, que aparecía en su moto cada vez con otra chica. Era considerado el pícaro, la oveja negra de la familia. Sobre todo cuando se le comparaba con su hermano, que era un abogado asentado, culto, que tocaba en la orquesta de la policía británica, el niño bueno de la familia. El hermano de Imre estaba siempre enojado con él, no le gustaban su carácter. Tampoco a los británicos les caía bien». ${ }^{77}$

La decisión de Jacobi de afiliarse al partido comunista se derivaba en gran medida de su resistencia ante la llegada de los nazis al poder en Alemania y la represión de la clase obrera en Viena. Es posible que jugara en Maccabi Tel Aviv como un intento (fallido) de ocultar a las autoridades británicas su identidad político-ideológica. Resulta interesante que el periódico polaco en ídish Haynt afirmase que «su comunismo es más romántico que ideológico». En el otoño de 1935 comentaba Haynt que la policía de Tel Aviv sospechaba que Jacobi, de la selección de motociclistas de Maccabi, estaba involucrado en una red comunista. En una pesquisa en su casa se encontraron sellos con la rúbrica del Alto Comisionado para Palestina y del cónsul de Francia. Asimismo fueron incautados materiales químicos y pasaportes falsificados de Palestina, Polonia, Hungría y Checoslovaquia. ${ }^{78}$

En las prisiones del Mandato, Jacobi sufrió la mano dura de sus guardianes, que lo acusaban de haber empleado la violencia contra ellos. La policía incautó sus escasas pertenencias y la «asistencia roja» del partido se movilizó para ayudarle en los periodos en que estaba libre. En junio de 1936 Jacobi, junto con Robert Aquist fue expulsado de Palestina por los británicos y zarpó desde Haifa rumbo a España. Ambos se sumaron a las Brigadas Internacionales. Jacobi estuvo en el batallón alemán Thälmann hasta febrero de 1937, en que fue herido en Jarama, aparentemente por

75 Dvorin \& Goldberg, 2011, p. 50.

76 Yahav, 2008, p. 216.

77 Yahav, 2008,pp. 216-217.

${ }^{78}$ Haynt, 23.9.1935, p. 3; Doar Hayom, «Orden de captura contra los dirigentes del nido comunista en el país», 22.8.1935, p. 8. 
un mortero mientras iba en su moto con órdenes de la comandancia hacia el frente, falleciendo en el hospital de campaña aledaño a Madrid. Según una carta enviada por su sobrino, Haggai Jacobi, a Zalman Saltzman, secretario de la Asociación Israelí de Combatientes en las Brigadas Internacionales, en junio de 1986, Imre fue enterrado en un suburbio de la capital de España. ${ }^{79}$

\section{Conclusiones}

La Olimpiada Popular, a la que los nacionalistas se referían como una amplia operación de propaganda internacionalista, masona y judía, destinada a convertir a España en un bastión bolchevique, no llegó a realizarse. ${ }^{80} \mathrm{Sin}$ embargo, el recuerdo del intento de crear un reto a los JJ.OO. de Berlín no desapareció. El movimiento deportivo obrero tampoco terminó con la sublevación de julio de 1936. Un año después se celebró una Olimpiada Popular en Amberes con la cooperación de la Internacional de Deportes Socialista y la Internacional de Deportes Comunista, con la participación de 27.000 atletas de 17 países. En esa ocasión hubo también una delegación soviética y una delegación republicana española, representando al país donde se libraba una guerra cruel.

En la Palestina judía, el partido político hegemónico y sus órganos de prensa se sumaron al boicot internacional contra los Juegos Olímpicos de Berlín. En la federación deportiva de Hapoel decidieron por lo tanto enviar una delegación para participar en la Olimpiada Popular de Barcelona, expresar su actitud antifascista y manifestar la posición sionista en el cada vez más agudo conflicto entre judíos y árabes en Palestina. Hapoel organizó un grupo de más de veinte atletas judíos, destacándose entre ellos los mejores futbolistas de aquellos años así como ex campeones europeos que se habían trasladado a Palestina poco tiempo antes.

Solo los dirigentes de la delegación llegaron a Barcelona, mientras que los atletas se quedaron varados en la frontera Francesa por el estallido de la Guerra Civil. Las fuentes en hebreo que hemos utilizado en este texto dan testimonio de la experiencia de estos atletas y sus representantes durante las primeras horas del alzamiento franquista en Cataluña y a

79 Hagai Jacobi a Zalman Zaltsman, junio de 1986. Agradezco a Eran Torbiner por haberme facilitado una copia de la carta.

${ }^{80}$ Para un aporte reciente, ver Physick, 2017, pp. 51-75. 
su vez de aspectos poco conocidos de la organización de los Juegos Populares en aquellos momentos decisivos. De esta manera el presente articulo ha intentado ampliar el conocimiento acerca de un episodio ideológicodeportivo de 1936, central para el estudio de la historia social del deporte internacional en el periodo de entre guerras.

Algunos de los atletas llegados a Barcelona para los frustrados Juegos Populares se quedaron en España y se transformaron en los primeros voluntarios internacionales que se sumaron a la defensa de la Republica. Tres de estos atletas -Elkon, Weiss y Jacobi- habían desarrollado su carrera deportiva en la Palestina judía. Estos tres voluntarios marcaron el rumbo a decenas de otros jóvenes judíos, la mayor parte de ellos de tendencias comunistas y algunos, como David Karon, vinculados al sionismo socialista, que también fueron a España a combatir en las filas republicanas. Todos aquellos jóvenes dejaron atrás la lucha entre judíos, árabes y británicos y llegaron a la península ibérica con la esperanza de detener con sus cuerpos la ola fascista que amenazaba con inundar Europa.

\section{Bibliografía}

Fuentes primarias

Leni Riefenstahl - Olympia - Festival de las Nacions (1936).

Archivos

Olimpiada Popular de Barcelona, Comité Organizador, Servicio de Prensa.

Biblioteca digital de la Universidad de Warwick.

Archivo Lavón de Historia del Partido Laborista Haavodá (Tel Aviv).

Prensa

Davar [en hebreo].

Doar Hayom [en hebreo].

Haaretz [en hebreo].

Hashomer Hatzair [en hebreo]. 
Haynt.
Kol Haam [en hebreo].
La Vanguardia.
La Veu de Catalunya.
L'Humanité.
Mundo Deportivo.
Mundo Obrero.
Sport Haboker [en hebreo].

Fuentes secundarias

ALEXANDER, Martin S. \& Helen GRAHAM (eds.), The French and Spanish Popular Fronts. Comparative Perspectives, Cambridge University Press, Cambridge, 1989.

CASADO HENÁNDEZ, Maria, «The Popular Olympiad (Barcelona 1936) in the Spanish Press,» en GONZÁLEZ AJA, Teresa (ed.), Comité Europeo de Historia del Deporte, Actas V Congreso de Historia del Deporte en Europa, Universidad Politécnica Madrid, Madrid, 2002, pp. 627-632.

CENTNER, Israel. De Madrid a Berlín, Publicado por el autor, Tel Aviv 1966 [en hebreo].

CLAY LARGE, David, Nazi Games: The Olympic of 1936, Norton, New York, 2007.

COLOMÉ, Gabriel, «La Olimpiada Popular de 1936: deporte y política», Documento de trabajo N. ${ }^{\circ}$ 264, Institut de Ciencies Politiques I Socials, Barcelona 2008.

DVORIN, Dani \& Asher GOLDBERG, Maccabi Tel Aviv: Los primeros 100 años, Media, Tel Aviv 2011[en hebreo].

GOTTLIEB, Moshe, «The American Controversy over the Olympic Games», American Jewish Historical Quarterly, LXI, March 1972, pp. 181-213.

GOUNOT, André, «El Proyecto de la Olimpiada Popular en Barcelona (1936), entre internacional y republicanismo regional», Cultura, Ciencia y Deporte, Vol. 1, N. ${ }^{\circ}$ 3, 2005, pp. 115-123.

GUTTMANN, Allen, «The 'Nazi Olympics' and the American Boycott Controversy», en ARNAUD, Pierre \& James RIORDAN (eds.), Sports and International Politics, E \& FN Spon, London, 1999, pp. 31-50.

HARIF, Haggai, Zionism of Muscles: The Political Functions of Representative Sport in Eretz Israel and in the State of Israel, 1898-1960, Yad Ben-Zvi, Jerusalén, 2011 [hebreo].

HART-DAVIS, Duff, Hitler's Games: The 1936 Olympics, Century, London, 1986. 
JONES, Stephen G., Sport, Politics and the Working Class: Organized Labour and Sport in Inter-War Britain, Manchester University Press, Manchester, 1988.

KAUFMAN, Haim, «Maccabi versus Hapoel: The Political Divide that Developed in Sports in Eretz Israel, 1926-1935», Israel Affairs, Vol. 13, 2007, pp. 554-565.

KIDD, Bruce, «Canadian Opposition to the 1936 Olympics in Germany», Canadian Journal of the History of Sport and Physical Education, IX, December 1978, pp. 20-40.

KIDD, Bruce, «The Popular Front and the 1936 Olympics», Canadian Journal of the History of Sport and Physical Education, XI, May 1980, pp. 1-18.

KIDD, Bruce, "Another World is Possible’: Recapturing Alternative Olympic Histories, Imagining Different Games», Global Olympics: Historical and Sociological Studies of the Modern Games, número especial de Research in the Sociology of Sport, Vol. 3, 2013, pp. 503-514.

KOWALSKY, Daniel, Stalin and the Spanish Civil War, Columbia University Press, New York, 2004.

MANDELL, Richard D., The Nazi Olympics, University of Illinois Press, New York, 1971.

MARTIN, Paul K., «Spain's Other Olympics», History Today, No. 42, Aug. 1992, pp. 6-8.

MURRAY, William J., «The French Workers' Sports Movement and the Victory of the Popular Front in 1936», International Journal of History of Sport, Vol. 19, No. 1, 1992, pp. 29-49.

PACUET, Rafael \& Enric PUJOL (comps.), La revolució del bon gust. Jaume Miravitlles i el Comissariat de Propaganda de la Generalitat de Catalunya (1936-1939), Viena Edicions, Barcelona, 2007.

PAYNE, Stanley G., The Spanish Civil War, the Soviet Union, and Communism, Yale University Press, New Haven, 2004.

PAZ, Israel \& Uriel ZIMRI, Chaim cumple 80: compañeros cuentan sobre Chaim Glowinsky al cumplir 80 años, Instituto Wingate, s/1, 1982 [en hebreo].

PHYSICK, Ray, «The Olimpiada Popular: Barcelona 1936, Sport and Politics in an Age of War, Dictatorship and Revolution», Sport in History, Vol. 37, No. 1, 2017, pp. 51-75.

PRESTON, Paul, «Spain's October Revolution and the Rightist Grasp for Power», Journal of Contemporary History, Vol. 10, No. 4, 1975, pp. 555578.

PUJADAS, Xavier \& Carles SANTACANA, L’altra olimpiada. Barcelona `36, Llibres de l'Índex, Barcelona, 2006.

REIN, Raanan, «Las repercusiones de la guerra civil española en Palestina: sionistas y comunistas, judíos y árabes», Revista de Historia Contemporánea, No. 38, 2009, pp. 89-112. 
REIN, Raanan, «A Belated Inclusion: Jewish Volunteers in the Spanish Civil War and Their Place in the Israeli National Narrative», Israel Studies, Vol. 17, No. 1, Spring 2012, pp. 24-49.

REIN, Raanan \& Inbal OFER, «Becoming Brigadistas: Jewish Volunteers from Palestine in the Spanish Civil War», European History Quarterly, Vol 46, No. 1, January 2016, pp. 92-112.

RICHARDSON, Dan, Comintern Army: The International Brigades and the Spanish Civil War, University Press of Kentucky, Lexington, 1982.

SHAPIRO, Edward S., «The World Labor Athletic Carnival of 1936: An American Anti-Nazi Protest», American Jewish History, Vol. 74, No. 3, 1985, pp. 255-273.

SHUBERT, Adrian, The Road to Revolution in Spain: The Coal Miners of Asturias, 1860-1934, University of Illinois Press, Urbana, 1987.

STEINBERG, David A., «The Workers' Sport Internationals, 1920-1928», Journal of Contemporary History, Vol. 13, 1978, pp. 233-251.

STEINBERG, David A., «Workers' Sport and the United Front, 1934-1936», Arena Review, Vol. 4, No. 1, 1980, pp. 1-6.

STOUT, James E., «Breakaway Nations: The Use of Sport and Physical Culture to Create a Cross-Class Catalan Identity during the Second Republic», tesis doctoral inédita, University of California, San Diego, 2016.

THALMANN, Clara \& Paul, Clara und Paul Thalmann: Revolution für die Freiheit. Stationen eines politischen Kampfes. Moskau/Madrid/Paris, Trotzdem Verlag, Grafenau 1985.

WALTERS, Guy, Berlin Games. How the Nazis Stole the Olympic Dream, William Morrow, New York, 2006.

WHEELER, Robert F., «Organized Sport and Organized Labour: The Workers' Sport Movement», Journal of Contemporary History, Vol. 13, 1978, pp. 191-210.

WULLSCHLEGER, Max (ed.), Schweizer Kämpfer in Spanien, Buchhandlung Stauffacher, Zurich, 1939.

YAHAV, Dan. También estos son héroes: voluntarios de Eretz Israel en las Brigadas Internacionales, 1936-1938, Tcherikover, Tel Aviv, 2008 [en hebreo]).

\section{Financiación}

El autor agradece al Israel Institute de Washington cuyo apoyo ha posibilitado la investigación para este artículo. 
El desafío a los Juegos Olímpicos de Berlín 1936...

\section{Datos del autor}

Raanan Rein es Profesor y Doctor en Historia, Vicepresidente de la Universidad de Tel Aviv y director del Centro S. Daniel Abraham de Estudios Internacionales y Regionales de la misma Universidad. Condecorado por el gobierno argentino como comendador de la Orden del Libertador General José de San Martin y por el Rey de España como comendador en la Orden del Mérito Civil. Es miembro correspondiente en Israel de la Academia Nacional de la Historia de la Argentina. Entre sus libros destacan: La salvación de una dictadura: Alianza Franco-Perón, 1946-1955 (1995); Franco, Israel y los judíos (1996); Guerra Civil y franquismo (compilado con Joan María Thomas, 2016). 